\title{
CHARACTERISATION OF AROMA-ACTIVE COMPOUNDS IN COMMERCIAL AGED RUMS
}

\author{
J.A. Pino ${ }^{a^{*}, \text { P. Winterhalter }}{ }^{\mathrm{b}}$, R. GöK ${ }^{\mathrm{b}}$ and J.C. GonzÁlez ${ }^{\mathrm{a}}$ \\ ${ }^{a}$ Food Industry Research Institute, Carretera al Guatao km 31/2, C.P. 19200, Havana. Cuba \\ ${ }^{\mathrm{b}}$ Institute of Food Chemistry, Technische Universität Braunschweig, Schleinitzstraße 20, DE-38106 Braunschweig. \\ Germany.
}

(Received: 24 May 2016; accepted: 8 July 2016)

The volatile compounds in commercial rums declared as aged 3, 7, 10, and 15 years were isolated by solvent extraction followed by solvent-assisted flavour evaporation and analysed by gas chromatography-olfactometry. According to the aroma extract dilution analysis, 19 potentially aroma-active compounds in the flavour dilution (FD) factor range of 8 to 1024 were found. Fifteen of them were present in at least one aged rum at FD factor $\geq 128$. Clear differences in the FD factors of these odourants between each of the aged rums suggested that they contributed to their unique sensory profiles.

Keywords: rum, aging, gas chromatography-olfactometry, aroma extract dilution analysis, solvent-assisted flavour evaporation

Rum is a spirit obtained by distillation of sugar cane molasses, after fermentation with yeast, and subsequent aging in oak barrels, where the spirit finally acquires its special characteristics of flavour and aroma during the time it is in contact with the wood. This stage, also termed maturation or aging, where the spirit extracts a series of compounds from the wood that have a positive influence on the sensory characteristics of the final product, together with the fermentation and distillation, are the most important stages in the presence of different volatile compounds (NicOL, 2003; PERSAD-DoODNATH, 2008). This is particularly important in the production of high quality Cuban rums. Today, the distillation of Cuban rum is mostly done in stainless steel columns and most rums are aged in white American oak barrels previously used for the aging of whiskey (SAMPAIO et al., 2008).

Numerous publications have dealt with the identification of volatile components in rum from different origins so far (NYKÄNEN \& NYKÄNEN, 1991; PINO, 1996, 2007; PINO et al., 1999, 2002; CArdoso et al., 2003; De Souza et al., 2006; Queris et al., 2007; Nascimento et al., 2008; SAMPAIO et al., 2008), but only few studies have made efforts to evaluate the aroma contribution of the individual volatile compounds (De Souza et al., 2006; Pino, 2007). DE SouzA and co-workers (2006) used GC-O with CharmAnalysis to detect $\beta$-damascenone, 1,1-diethoxyethane, ethyl 2-methylbutanoate, ethyl 2-methylpropanoate, ethyl butanoate, oak lactone, vanillin, and two unknown compounds as the most potent odourants in a Puerto Rican rum of unknown aging time. Recently, PINO and co-workers (2012) used solvent extraction followed by solvent-assisted flavour evaporation (SAFE) in combination with $\mathrm{GC}-\mathrm{O}$ with aroma extract dilution analysis (AEDA) and odour activity values measurements to find the potentially odour-active compounds in a non-commercial 15 years aged Cuban

\footnotetext{
* To whom correspondence should be addressed. Phone: +53 72793956; e-mail: jpino@iiiia.edu.cu
} 
rum. Nineteen odourants ethanol, $(E)-\beta$-damascenone, ethyl butanoate, ethyl hexanoate, vanillin, cis-oak lactone, ethyl 2-methylpropanoate, 1,1-diethoxyethane, ethyl 2-methylbutanoate, 3-methylbutyl acetate, ethyl octanoate, ethyl decanoate, 2-phenylethyl acetate, 2-phenylethanol, 2-methoxyphenol, 4-ethyl-2-methoxyphenol, 4-propyl-2methoxyphenol, $\gamma$-nonalactone, and eugenol were considered as most odour-active volatiles in this aged rum.

Because the knowledge on the key odourants in the final product is the prerequisite for studies on the influence of processing steps, the aim of the present study was to apply a comparative AEDA on the volatiles obtained by SAFE distillation from four commercial aged rums with different maturation times and sensory profiles. To our knowledge, there is only one report on the aroma-active compounds in aged rum that employs the SAFE isolation technique to date (PINO et al., 2012).

\section{Materials and methods}

The commercial aged rums (40\% v/v alcohol) under investigation were obtained from the high-quality market in Cuba. They had been produced by stainless-steel column distillation (continuous process) and had been stored in heat charred oak casks (200 1 capacity) for long time (FARIA, 2011). These rums were adequately blended to produce commercial products with declared aged years of 3, 7, 10, and 15. Six bottles for each age were blended for analysis.

Reference compounds of the odourants identified were obtained from the commercial sources given in parentheses: 1,1-diethoxyethane, ethyl 2-methylpropanoate, ethyl butanoate, ethyl 2-methylbutanoate, 3-methylbutyl acetate, ethyl hexanoate, ethyl octanoate, ethyl decanoate, ethyl phenylacetate, 2-phenylethanol, 5-methyl-2-furfural, cis-oak lactone, 4-ethyl-2-methoxyphenol, 4-propyl-2-methoxyphenol, eugenol, $\gamma$-nonalactone, and vanillin (Sigma-Aldrich, St. Louis, MO); 2-methoxyphenol (Merck, Darmstadt, Germany); and (E)$\beta$-damascenone was a gift from Dallant (Barcelona, Spain). Pentane, diethyl ether, anhydrous sodium sulphate, and absolute ethanol were obtained from Merck (Darmstadt, Germany). A $\mathrm{C}_{8}-\mathrm{C}_{32} n$-alkane mixture, used for determination of linear retention indices was obtained from Sigma-Aldrich (St. Louis, MO).

The procedure was the same as previously described (MunAfo et al., 2014). Rum samples $(15 \mathrm{~g})$ were placed into $20 \mathrm{ml}$ borosilicate glasses. Samples were orthonasally evaluated by free choice profiling and in a quantitative descriptive analysis (QDA) by a trained sensory panel of five experienced panellists (mean age 27 years, 60\% male). The descriptors used in the QDA were defined on the basis of the odour of a reference compound dissolved in ethanol $40 \%, \mathrm{v} / \mathrm{v}$ at a concentration of 100 times above the respective threshold value or using a reference material, according to the standard procedure used in the rum industry. The reference compounds were vanillin (vanilla) and ethyl butanoate (fruity). The reference materials used to define some attributes were wood (an oak chip macerate in $40 \%$ $\mathrm{v} / \mathrm{v}$ alcohol), dry fruit ( $5 \mathrm{~g}$ of raisin fruit in ethanol $40 \% \mathrm{v} / \mathrm{v}$ ), caramel (caramel syrup diluted in ethanol $40 \% \mathrm{v} / \mathrm{v}$ ), and raw spirit (fresh rum distillate $40 \% \mathrm{v} / \mathrm{v}$ alcohol). Panellists rated the descriptor for each of the samples on a continuous $15 \mathrm{~cm}$-scale in increments from 0 to 15 $(0=$ not detectable and $15=$ strong $)($ ISO, 2003).

The isolation procedure was the same as previously reported (PINO et al., 2012). The volatiles in rums $(100 \mathrm{ml})$ were isolated by extraction of a 1:1 dilution with Milli-Q water 
(saturated with $\mathrm{NaCl})$ using diethyl ether-pentane $(1: 1)(3 \times 50 \mathrm{ml})$. Before, $50 \mu \mathrm{l}$ of a standard solution of methyl octanoate $\left(0.02 \mathrm{~g} \mathrm{ml}^{-1}\right)$ were added. The combined extracts were dried over anhydrous sodium sulphate and concentrated (nearly $38^{\circ} \mathrm{C}$ ) to $100 \mathrm{ml}$ using a Vigreux column $(30 \mathrm{~cm} \times 1 \mathrm{~cm}$ i.d.). The nonvolatile compounds were removed by high vacuum distillation $\left(10^{-3}-10^{-4} \mathrm{~Pa}\right)$ using the SAFE apparatus (ENGEL et al., 1999), and the distillate was concentrated to $200 \mu \mathrm{l}$ in a bath heated to $40{ }^{\circ} \mathrm{C}$ using the same Vigreux column. All volatile compounds from rum samples were evaluated by three experts by smelling a drop of the extract on a cardboard smelling strip as done by perfumers. After evaporation of the solvent, all experts agreed that the extract evoked the characteristic aroma of rum, thereby indicating that the method used for aroma isolation was appropriate.

GC-MS was performed with a HP-6890 instrument gas-chromatograph (HewlettPackard Co., Palo Alto, CA) interfaced with a HP-5973 mass-selective detector fitted with DB-Wax (30 $\mathrm{m} \times 0.25 \mathrm{~mm}, 0.25 \mu \mathrm{m}$ film thickness; J \& W Scientific, Folsom, CA) or a DB$5 \mathrm{~ms}(30 \mathrm{~m} \times 0.25 \mathrm{~mm}, 0.25 \mu \mathrm{m}$ film thickness; J \& W Scientific, Folsom, CA) capillary column, working with the following temperature programme and conditions for both columns: $50{ }^{\circ} \mathrm{C}$ for $2 \mathrm{~min}$, ramp of $4{ }^{\circ} \mathrm{C} \cdot \mathrm{min}^{-1}$ up to $240{ }^{\circ} \mathrm{C}$; injector temperature $250{ }^{\circ} \mathrm{C}$; carrier gas helium at $1 \mathrm{ml} \mathrm{min}{ }^{-1}$; transfer line temperature $240{ }^{\circ} \mathrm{C}$; injections $1 \mu \mathrm{lin}$ split mode with 1:10 ratio. The detection by the mass spectrometer was performed in the electron impact (EI) ionisation mode at $70 \mathrm{eV}$. The acquisition was performed in scanning mode (mass range $\mathrm{m} / \mathrm{z} 35-400 \mathrm{amu}$ ). Identification of the constituents was based on comparison of the linear retention indices with those of authentic samples and on computer matching against commercial libraries (NIST02, Wiley 275, Palisade 600 and ADAMS, 2001) and FLAVORLIB homemade library mass spectra built up from pure substances. Identifications were confirmed by the injection of the chemical standards into the GC-MS system. Linear retention indices of the compounds were calculated using an $n$-alkane series.

$\mathrm{GC}-\mathrm{O}$ analyses were performed with a gas chromatograph Konik 4000 A instrument (Konik, Barcelona) equipped with a DB-Wax $(30 \mathrm{~m} \times 0.25 \mathrm{~mm}, 0.25 \mu \mathrm{m}$ film thickness; J \& W Scientific, Folsom, CA) or a DB-5ms (30 m×0.25 mm, $0.25 \mu \mathrm{m}$ film thickness; J \& W Scientific, Folsom, CA) capillary column. Analytical conditions were the same as for the GCMS analysis. The end of the capillary column was connected to a deactivated Y-shaped glass splitter dividing the effluent into two equal parts, which were transferred via two deactivated fused silica capillaries $(50 \mathrm{~cm} \times 0.25 \mathrm{~mm})$ to a sniffing port and an FID, respectively. The sniffing port, mounted on a detector base of the GC, consisted of a cylindrically shaped aluminum device with a bevelled top and a central drill hole housing the capillary. Nitrogen $\left(30 \mathrm{ml} \cdot \mathrm{min}^{-1}\right)$ was used as makeup gas. The injection volume was $1 \mu \mathrm{l}$. During a $\mathrm{GC}-\mathrm{O}$ run, the nose of the panellist was placed closely above the top of the sniffing port and the odour of the effluent was evaluated. Sniffing time was about $30 \mathrm{~min}$ for each assessors. Detected odours (quality and retention times) were marked in the chromatogram. The sniffing port temperature was at $240{ }^{\circ} \mathrm{C}$. The $\mathrm{GC}-\mathrm{O}$ analyses were performed in triplicate by two experienced assessors. Each one had a minimum of $20 \mathrm{~h}$ of previous $\mathrm{GC}-\mathrm{O}$ sniffing experience and they had also previously taken part in a sensory descriptive analysis training and had actively contributed to the development of the descriptive sensory vocabulary.

Aroma isolates were diluted with diethyl ether-pentane (1:1) to obtain serial dilutions of $1: 2,1: 4,1: 8, \ldots, 1: 1024$ of the original extract. Each dilution was submitted to GC-O, using capillary DB-Wax. Some dilutions $(1: 64,1: 128,1: 256,1: 512$, and 1:1024) were also analysed by GC-O using the DB-5ms column and the conditions described above. Analytical conditions were the same as for GC-MS analyses. To each aroma-active region for each sample was 
assigned an FD factor corresponding to the dilution factor of the highest diluted sample in which the odour was detectable (SCHIEBERLE, 1995).

\section{Results and discussion}

Samples of each of the four commercial aged rums were evaluated by trained panellists, first using free-choice profiling and then a QDA(Fig. 1). The aroma of 3-years rum was considered as typical rum aroma with a strong raw spirit note, whereas the scores of the other aroma notes were rather low in this sample. Seven-year rum presented a typical aged rum aroma, but was less in raw spirit note than 3-year rum. It also showed a caramel note that distinguished it from all the other rums investigated. The sensory profile of 10 -year rum was dominated by a vanilla odour note, with dry fruit, woody, fruity notes. The sensory profile of 15 -year rum comprised the characteristic very balanced aged rum profile with a pronounced woody note, and in particular an intense and unique dry fruit note, but lacking any special note, whereas the score of the raw spirit note was rather low in this sample.

The smell of the aroma isolates clearly represented the typical aroma profile of the corresponding aged rums. Therefore, aroma isolates were submitted to AEDA, which resulted in 19 aroma-active compounds in the FD factor range of 8 to 1024 (Table 1). The assignment of the structure of the odourous compounds was made by their retention indices, odour characteristics, and mass spectra in comparison with data obtained from reference substances.

Table 1 . Potentially aroma-active compounds $(\mathrm{FD} \geq 8)$ in commercial aged rums

\begin{tabular}{|c|c|c|c|c|c|c|c|}
\hline \multirow[t]{2}{*}{ Compound } & \multirow{2}{*}{$\begin{array}{l}\text { Odour } \\
\text { quality }^{\mathrm{a}}\end{array}$} & \multicolumn{2}{|c|}{$\mathrm{LRI}^{\mathrm{b}}$} & \multicolumn{4}{|c|}{ FD factor $^{\mathrm{c}}$} \\
\hline & & DB-Wax & DB-5ms & 3 years & 7 years & 10 years & 15 years \\
\hline 1,1-Diethoxyethane & fruity & 825 & 627 & 32 & 64 & 64 & 64 \\
\hline Ethyl 2-methylpropanoate & fruity & 957 & 750 & 32 & 128 & 128 & 128 \\
\hline 5-Methyl-2-furfural & caramel & 1543 & 965 & 8 & 256 & 128 & 256 \\
\hline Ethyl butanoate & fruity & 1030 & 804 & 32 & 128 & 128 & 256 \\
\hline Ethyl 2-methylbutanoate & fruity & 1049 & 851 & 32 & 64 & 128 & 128 \\
\hline 3-Methylbutyl acetate & banana-like & 1114 & 880 & 32 & 64 & 64 & 128 \\
\hline Ethyl hexanoate & fruity & 1218 & 1000 & 128 & 256 & 256 & 256 \\
\hline Ethyl octanoate & fruity & 1425 & 1195 & 128 & 256 & 512 & 512 \\
\hline Ethyl decanoate & brandy & 1637 & 1398 & 32 & 128 & 256 & 512 \\
\hline 2-Phenylethyl acetate & rose, honey & 1792 & 1260 & 16 & 32 & 32 & 64 \\
\hline (E)- $\beta$-Damascenone & baked-apple & 1805 & 1385 & 32 & 128 & 256 & 256 \\
\hline 2-Methoxyphenol & phenolic & 1859 & 1090 & 8 & 32 & 64 & 128 \\
\hline 2-Phenylethanol & floral & 1899 & 1107 & 16 & 32 & 32 & 64 \\
\hline cis-Oak lactone & woody, oaky & 1928 & 1315 & 128 & 512 & 1024 & 1024 \\
\hline$\gamma$-Nonalactone & coconut-like & 1995 & 1360 & 8 & 32 & 32 & 64 \\
\hline 4-Ethyl-2-methoxyphenol & spicy & 2000 & 1287 & 8 & 64 & 128 & 128 \\
\hline 4-Propyl-2-methoxyphenol & spicy & 2084 & 1463 & 8 & 64 & 128 & 128 \\
\hline Eugenol & spicy & 2151 & 1364 & 32 & 128 & 256 & 512 \\
\hline Vanillin & vanilla & 2550 & 1409 & 128 & 256 & 1024 & 1024 \\
\hline
\end{tabular}

a: Odour quality perceived at the sniffing port; ${ }^{\mathrm{b}}$ : LRI $=$ linear retention index; ${ }^{\mathrm{c}}$ : FD factor $=$ flavour dilution factor 


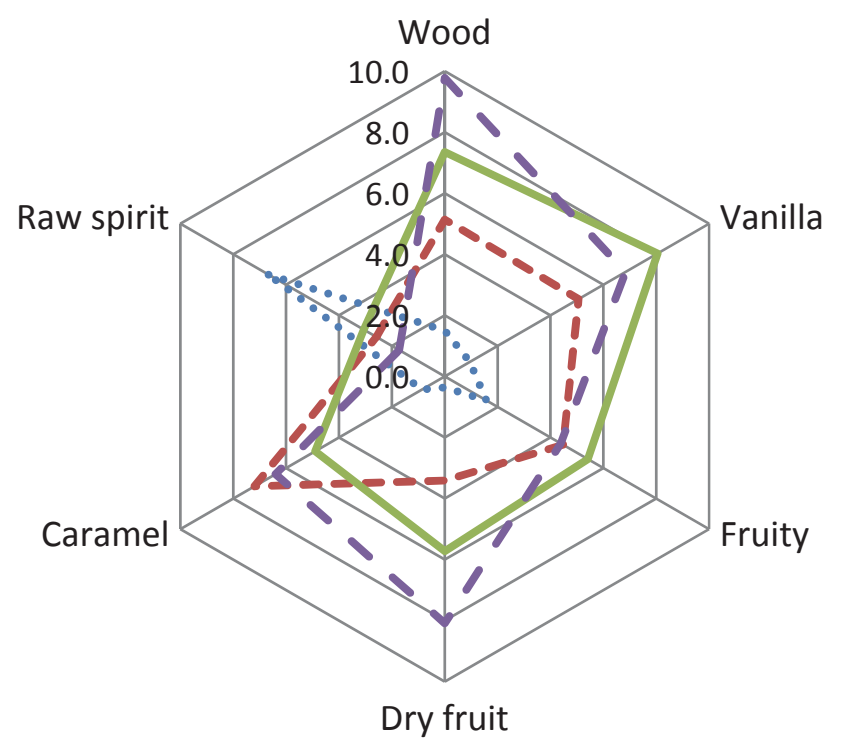

Fig. 1. Aroma profiles of commercial aged rums. Panellists rated the intensity of each attribute on a continuous $15 \mathrm{~cm}$-scale in increments from 0 to $15(0=$ not detectable and $15=$ strong $)$.

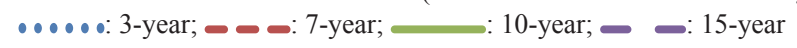

The results of the identification experiments combined with the FD factors showed that 15 compounds were the most potent aroma-active compounds in the four aged rums, all of which exhibited an FD factor of $\geq 128$ in at least one of the samples analysed. Among them, woody, oaky smelling cis-oak lactone and vanilla-like smelling vanillin exhibited the highest FD factor (1024) in the two most aged rums and relatively higher FD factors in the other two least aged samples. Therefore, these compounds might be major contributors to the characteristic aged rum aroma note common to all rums investigated. cis-Oak lactone and vanillin have been reported as major aroma-active compounds in rums before (DE SouzA et al., 2006; PINO et al., 2012).

High FD factors were determined for some fruity smelling esters including ethyl 2-methylpropanoate, ethyl butanoate, ethyl 2-methylbutanoate, 3-methylbutyl acetate, ethyl hexanoate, ethyl octanoate, and ethyl decanoate. These aliphatic esters most probably accounted for the general fruity note in the aged rum aroma profiles. All of them have already been described as aroma-active compounds in a non-commercial 15-year aged rum (PINO et al., 2012).

The dry fruit-like aroma note clearly found in 7-, 10-, and 15-year rums agreed quite well to high FD factors of $\beta$-damascenone, with a typical baked-apple odour, and known contributor to wine fruity and raisin character (SAN-JUAN et al., 2011). In the same way, the caramel-like aroma note detected in the three most aged rums agreed quite well to high FD factors of the caramel-like smelling 5-methyl-2-furfural. This furanic aldehyde has been reported in rum using the same isolation procedure (PINO et al., 2012), but up to now it has never been recognised as potentially aroma-active compound.

High FD factors were also found for some phenols including 2-methoxyphenol, 4-ethyl2-methoxyphenol, 4-propyl-2-methoxyphenol, and eugenol, which most probably are 
responsible for the spicy note, particularly in the most aged rums. These phenols have already been reported as aroma-active compounds in a non-commercial rum, aged 15-year (PINO et al., 2012).

Though many compounds were also detected as potent odourants in the 3-year aged rum, no such strong odour notes were present in the sensory profile of this sample, except the raw spirit note, probably due to a dominating aroma impression of 1-propanol, 2-methylpropanol, and 3-methylbutanol (named fusel alcohols), which are commonly present in all rums (PINO et al., 2012). This aroma impression is overlapped by other isolated compounds from the oak wood and other chemical reactions that occurred during the aging process (NYKÄNEN \& NYKÄNEN, 1991).

In future investigations, the role of individual odourants in the aroma of the four commercial aged rums, including the quantitation of odour-active compounds, aroma reconstitution experiments, and omission tests are needed to further characterise the differences between these rums.

\section{Conclusions}

The application of AEDA on the four commercial aged rums resulted in 19 odour-active compounds, among which 15 odourants were the potentially major aroma-active compounds. The procedure used here provided information about the compounds responsible for the typical olfactory profile of commercial aged rums and the constituents responsible for the aroma characteristics of the individual rums.

Author Jorge A. Pino acknowledges financial support of this work by the Institute of Food Chemistry, Technical University of Braunschweig, Germany.

\section{References}

AdAms, R.P. (2001): Identification of essential oil components by gas chromatography/quadrupole mass spectroscopy. Allured Publishing Co., Carol Stream, IL. 456 pages.

Cardoso, D.R., Bettin, S.M., Reche, R.V., Lima-Neto, B.S. \& Franco, D.W. (2003): HPlC-DAD analysis of ketones as their 2,4-dinitrophenylhydrazones in Brazilian sugar-cane spirits and rum. J. Food Comp. Anal., $16,563-573$.

De Souza, M.D.C.A., VÁsquez, P., Del Mastro, N.L., Acree, T.E. \& Lavin, E.H. (2006): Characterization of cachaça and rum aroma. J. Agr. Food Chem., 54, 485-488.

Engel, W., Bahr, W. \& Schieberle, P. (1999): Solvent assisted flavour evaporation - a new and versatile technique for the careful and direct isolation of aroma compounds from complex food matrices. Eur. Food Res. Technol., 209, 237-241.

FARIA, J.B. (2011): Sugar cane spirits: Cachaça and rum production and sensory properties. -in: PigGOTT, J. (Ed.) Alcoholic beverages: Sensory evaluation and consumer research. Elsevier, Amsterdam, The Netherlands, pp. $348-358$.

ISO (2003): Sensory analysis. Guidelines for the use of quantitative response scales. No. 4121

Munafo, J.P., Didzalis, J., Schnell, R.J., Schieberle, P. \& Steinhaus, M. (2014): Characterization of the major aroma-active compounds in the mango (Mangifera indica L.) cultivars Haden, White Alfonso, Praya Sowoy, Royal Special, and Malindi by application of a comparative aroma extract dilution analysis. J. Agr. Food Chem., 62, 4544-4551.

Nascimento, E.S.P., CArdoso, D.R. \& Franco, D.W. (2008): Quantitative ester analysis in cachaça and distilled spirits by gas chromatography-mass spectrometry (GC-MS). J. Agr. Food Chem., 56, 5488-5493. 
Nicol, D.A. (2003): Rum. -in: LeA, A.G.H. \& Piggott, J.R. (Eds) Fermented beverage production. Kluwer Academic, New York, pp. 263-287.

Nykänen, L. \& Nykänen, I. (1991): Distilled beverages. -in: MAarse, H. (Ed.) Volatile compounds in foods and beverages. Marcel Dekker Inc., New York, pp. 547-580.

Persad-Doodnath, V. (2008): From sugar to rum - the technology of rum making. -in: Bryce, J.H., Stewart, G.G. \& Piggott, J.R. (Eds) Distilled spirits production, technology and innovation. Nottingham University Press, Nottingham, UK, pp. 159-167.

Pino, J. (1996): Los componentes volátiles del aroma del ron (The volatile constituents of rum). Alimentaria, 33, 79-85.

Pino, J., Marbot, R., Pérez, J. \& Nuñez, M. (1999): Application of multivariate statistical methods to the differentiation of rum aged in two types of oak barrels. J. Food Qual., 22, 183-192.

Pino, J., Martí, M.P., Mestres, M., Pérez, J., Busto, O. \& Guasch, J. (2002): Headspace solid-phase microextraction of higher fatty acid ethyl esters in white rum aroma. J. Chromatogr. A, 954, 51-57.

Pino, J. (2007): Characterization of rum using solid-phase microextraction with gas chromatography-mass spectrometry. Food Chem. 104, 421-428.

Pino, J., Tolle, S., GöK, R. \& Winterhalter, P. (2012): Characterisation of odour-active compounds in aged rum. Food Chem., 132, 1436-1441.

Queris, O., Pino, J., Martí, M.P. \& Rodríguez, I. (2007): Packed bed techniques for accelerated aging of rum. Rev. CENIC Cienc. Quím., 38, 319-324.

Sampaio, O.M., Reche, R.V. \& Franco, D.W. (2008): Chemical profile of rums as a function of their origin. The use of chemometric techniques for their identification. J. Agr. Food Chem., 56, 1661-1668.

San-Juan, F., Ferreira, V., Cacho, J. \& Escudero, A. (2011): Quality and aromatic sensory descriptors (mainly fresh and dry fruit character) of Spanish red wines can be predicted from their aroma-active chemical composition. J. Agr. Food Chem., 59, 7916-7924.

SChieberle, P. (1995): New developments in methods for analysis of volatile flavor compounds and their precursors. -in: GaOnKar, A. (Ed.) Characterization of food: Emerging methods. Elsevier, Amsterdam, The Netherlands, pp. 403-431 